\title{
Família e instituições de acolhimento nos cuidados a adolescentes vítimas de incesto
}

\section{Family and host institution in caring for incest victims}

\section{Familia y instituciones de acogida en los cuidados a adolescentes víctimas del incesto}

\author{
Aline Luiza de Carvalho* \\ Pontifícia Universidade Católica de Minas Gerais - PUC/MG, Belo Horizonte, Minas \\ Gerais, Brasil
}

\section{Márcia Stengel**}

Pontifícia Universidade Católica de Minas Gerais - PUC/MG, Belo Horizonte, Minas Gerais, Brasil

\begin{abstract}
RESUMO
Mesmo com as mudanças atuais em sua estrutura, papéis e funções, a família ainda mantém sua importante contribuição na formação subjetiva dos seus membros, embora vá perdendo sua centralidade. Quando nela apresenta relações conflituosas, admitindo a distorção de conceitos e valores entre o grupo, apresentam-se ainda mais dificuldades de convívio. Diante disto, como avaliar a experiência do incesto na representação deste grupo? Como ponderar a percepção e mudanças das rotinas quando as jovens, que sofreram com a violência sexual intrafamiliar, saem de suas residências para viver em uma instituição? E repercussões da triangulação (adolescente, família e instituição)? Buscou-se, portanto, aproximar esta realidade, comum às vítimas de violência, objetivando compreender o vínculo que se estabelece entre estas três representações. Observou-se que a situação de acolhimento institucional as tiram da história já constituída e as coloca em um outro lugar, para elas inseguro e incerto, onde são obrigadas a deixar suspensas a vida e relações anteriores, para conviver com pessoas não conhecidas até a solução do caso. Verificou-se dificuldades de manutenção das antigas e estabelecimento de novas relações, considerando fragilização dos laços desde a separação familiar, das dificuldades de identificação institucional e de estabelecimento de referências contínuas.
\end{abstract}

Palavras-chave: família, abrigamento, adolescência, incesto.

\begin{abstract}
Even with the current changes in its structure, roles and functions, the family still maintains its important contribution in the subjective formation of its members, although it loses its centrality. When it presents conflicting relationships, admitting the distortion of concepts and values among the group, there are even more difficulties of conviviality. In view of this, how can we evaluate the experience of incest in the representation of this group? How can we ponder the perception and changes in routines when young
\end{abstract}


women who have suffered from intrafamily sexual violence leave their homes to live in an institution? And repercussions of triangulation (teen, family and institution)? We sought, therefore, to bring this reality, common to victims of violence, in order to understand the bond established between these three representations. It was observed that the institutional reception situation removes them from the history already constituted and places them in another place, for them insecure and uncertain, where they are forced to leave suspended the life and previous relations, to live with people not known until the solution of the case. There were difficulties in maintaining the old ones and establishing new relationships, considering the weakening of ties since the family separation, the difficulties of institutional identification and the establishment of continuous references.

Keywords: family, shelter, adolescence, incest.

\section{RESUMEN}

A pesar de los cambios actuales en su estructura, papeles y funciones, la familia todavía mantiene su importante contribución en la formación subjetiva de sus miembros, aunque va perdiendo su centralidad. Cuando en ella presenta relaciones conflictivas, admitiendo la distorsión de conceptos y valores entre el grupo, se presentan aún más dificultades de convivencia. Ante esto, ¿cómo evaluar la experiencia del incesto en la representación de este grupo? ¿Cómo ponderar la percepción y cambios de las rutinas cuando las jóvenes, que sufrieron con la violencia sexual intrafamiliar, salen de sus residencias para vivir en una institución? ¿Y repercusiones de la triangulación (adolescente, familia e institución)? Se buscó, pues, aproximar esta realidad, común a las víctimas de violencia, objetivando comprender el vínculo que se establece entre estas tres representaciones. Se observó que las situaciones de acogida institucional las sacan de la historia ya constituida y las coloca en otro lugar, para ellas inseguro e incierto, donde están obligadas a dejar suspendidas la vida y relaciones anteriores, para convivir con personas no conocidas hasta la solución del caso. Se constataron dificultades de mantenimiento de las antiguas y establecimiento de nuevas relaciones, considerando fragilización de los vínculos desde la separación familiar, de las dificultades de identificación institucional y de establecimiento de referencias continuas.

Palabras clave: familia, vivienda, adolescencia, incesto.

\section{Introdução}

As constantes mudanças que ocorrem na adolescência a delineiam como um período complexo. Podemos apresenta-la por diversos aspectos, seja por uma visão naturalista ou mesmo por uma concepção que considera a construção subjetiva advinda da sua história e relações vividas. No entanto, os estudiosos concordam entre si quando a aponta como um momento característico de alterações biopsicossociais necessárias para o processo de amadurecimento para a fase adulta.

Atentando as peculiaridades dos estudos apresentados, podemos situá-la como um período em que o jovem conta com a ruptura das comodidades da infância e os ensaios de responsabilidades da vida adulta. É neste tempo em que se percebe aumento de atividades 
sociais importantes e experiências de convívios variados, com grande significado na elaboração da identidade e formação psíquica do sujeito.

Durante o aflorar, os adolescentes, em geral, revelam preocupações diversas, descritas como incômodas, a exemplo da aparência, do peso, altura; apresentam irritação provocada pelas forças pulsionais intensas, que seriam, muitas vezes, responsáveis pelas ações impulsivas; sentimento de culpa procedente da reprovação, bem como do prazer que as descargas sexuais proporcionam; progressão do desenvolvimento mental, com a melhor utilização da percepção, imaginação, memória, lógica, atenção e maior riqueza de estímulos ambientais por passarem a participar de ambientes socioculturais mais amplos. Frente a tantas mudanças, observa-se a importância do convívio em família na formação de sujeitos.

A família, além de ser o primeiro sistema social no qual o ser humano é inserido, é Locus onde os indivíduos permanecem, em sua maioria, por significativa parte do tempo, subjetivando sua sobrevivência (em todos os aspectos que cabem a esta palavra), maturando em processos de aprendizagem variados para a sua adaptação social. Porém, na adolescência, a família é redimensionada a medida que eles começam a exercer e exigir o reconhecimento de sua participação nela.

Na qualidade de período de intensas experiências, a família perde a condição de orientação e ordem únicas, tal como ocupava na infância, e transforma-se em um outro lugar onde a relação entre pais e filhos, se tomada pela sua complexidade, pode ser tranquila como também marcada por conflitos e negociações (Stengel, 2003, p. 61). Estas divergências, entretanto, não implicam obrigatoriamente em prejuízos para a saúde mental dos sujeitos, pois é neste momento em que o jovem participa ativamente sobre a dinâmica da casa, das relações e demandas específicas do convívio.

Quando as opiniões não são exploradas, aparecem as consequentemente dificuldades de convívio ante a indefinição dos papéis de cada membro, o não partilhamento de conhecimentos, valores e com isso, a dificuldade na reconstrução identitária de todos. Esta confusão pode ser percebida em relações tumultuosas, com características autoritárias, negligenciadas, violentas, como observadas nas relações incestuosas, foco deste artigo.

Diante do exposto, e tendo em vista o resultado da pesquisa de mestrado, considerou-se algumas questões que são nosso objetivo neste artigo: o que ocorre quando a família não corresponde a estas características participativas e os filhos são acolhidos por instituições específicas? Que tipo de vínculos se observam em suas histórias, seja familiar ou os mantidos durante o seu estabelecimento na instituição? Estas e outras perguntas ficaram após a defesa da dissertação sobre 
os relacionamentos afetivo-sexuais de adolescentes vítimas de incesto ${ }^{1}$.

O direito à convivência familiar e comunitária é um dos pilares do Estatuto da Criança e do Adolescente (ECA) visando garantir o seu desenvolvimento pleno da infância, porém em levantamento nacional das crianças e adolescentes em Serviço de Acolhimento Institucional SAI, apresentam números significativos sobre o assunto: no Brasil há 2.624 Serviços de acolhimento em todo o território nacional, com capacidade de acolhimento total de 52.587 crianças e adolescentes. Até a publicação da pesquisa estes serviços tinham 36.929 crianças e adolescentes em situação de vulnerabilidade social e familiar utilizavam desse mecanismo como apoio (Assis \& Farias, 2013).

Aproveitando os dados das entrevistas com as adolescentes vítimas de violência sexual intrafamiliar e acolhidas em instituição, além de números relevantes de crianças e adolescentes em situação de vulnerabilidade acolhidas nos SAl (Assis \& Farias, 2013) torna-se importante trazê-la a discussão como encaminhamento comum a pessoas em situação de risco, assim como experiência que também repercute subjetivamente na formação e intepretação própria de conceitos, valores e relações entre todos os envolvidos.

Não se tem como objetivo esgotar a discussão sobre as repercussões das vivências incestuosa e de acolhimento institucional, papéis das famílias e casas de apoio, porém é de suma importância que haja uma definição papéis e de responsabilidades, além de conexão entre as ações de cada uma das partes: família, casa de apoio e sujeito.

\section{Família}

Objeto clássico das ciências sociais e humanas, a família é tida, em alguns estudos, como célula primeira de socialização e de formação subjetiva do sujeito. Além disso, é colocada como ponte entre a sociedade e o indivíduo, se empenhando a fazer a interposição entre o indivíduo e as normas culturais contidas em cada sociedade, a fim de colaborar com a manutenção da ordem social.

Para Porreca (2011) e Singly (2012) é importante considera-la como um grupo contextualizado e que tem uma história de evolução significativa em sua constituição: mudanças sócio-econômicas, aumento da perspectiva de vida e escolaridade, novas concepções sobre sexualidade e de identidade de gênero, autonomia, reconstituição estrutural, programação reprodutiva, dentre outros aspectos que representam o período em que vive. Com estas mudanças, foi inevitável considerar a redefinição de papéis, relacionais e sociais no seu funcionamento: 
Na realidade a família é o primeiro refúgio em que o indivíduo ameaçado se protege durante os períodos de enfrentamento do Estado. Mas assim que as instituições políticas lhes oferecem garantias suficientes, ela se esquiva da opressão da família e os laços de sangue se afrouxam. A história da linhagem é uma sucessão de contradições e distensões cujo ritmo sofrem modificações de ordem política. (Aries, 1981, p. 145).

Frente às mudanças políticas, sociais e culturais, passamos hoje por uma redefinição do modelo familiar nuclear patriarcal, assumindo novos formatos, contando com a participação de novos atores e instituições na educação da criança e do adolescente. Assegurar o cumprimento de tal função tem colocado em questão a eficácia da família e como essas novas formatações podem influenciar no cumprimento de suas funções.

O papel materno, em consonância com a representação simbólica do corpo feminino, caberia, além da função nutrícia, de agasalho e proteção da prole, uma função continente ou de receptáculo das angústias existenciais de que esteja correspondentemente no papel filial. Em contrapartida, o papel paterno, pelos mesmos condicionantes simbólicos da anatomofisiologia sexual, tocaria interpor-se entre mãe e filho para facilitar o processo de dessimbiotização e encaminhar a aquisição da identidade deste ao longo de seu desenvolvimento psicológico (ZAMBERLAN, 2006, p. 60).

A família contribui ao processo de desenvolvimento físico e psíquico necessário ao indivíduo e significativo às suas futuras vivências no meio social. Pode-se pensar com isso, que este é subsistema dinâmico associado às noções de valores, crescimento, mudança e adaptação entre os elementos envolvidos que ajudam a desenvolver e integrar os filhos ao sistema social mais amplo no qual se pode compartilhar experiências, formar sua identidade e adquirir características à elaboração psíquica.

Observa-se que apesar das significativas mudanças pelas quais a família passa nas últimas décadas, com alterações em sua configuração e sua dinâmica, ela ainda é evidenciada como centro de atenção por ser um dos espaços primários e privilegiados para a associação da vida psicológica, emocional e social de seus componentes.

Interligando as observações Porreca (2011), Sigly (2007) e Bowlby (2006) é possível apontar a importância do alicerce afetivo do grupo para que crianças e adolescentes se sintam seguros, conscientes de normas, dos modos relacionais, baseados no entendimento dos valores e tradições vivenciadas. A família, com isso, contribuirá aos 
filhos as bases psicológicas e emocionais na formação subjetiva, uma vez que é no lar que as pautas culturais, afetivas e sociais são vivenciadas e aprendidas.

Maria Rita Kehl (2003) contribui com essa perspectiva quando traz em seu texto uma análise simbólica e psicanalítica que expõe que é neste grupo que se constituirá o sujeito a medida que se expressa leis como a interdição do incesto e sexuação, pois somente com esta compreensão, pode-se preparar as crianças para suas responsabilidades em relação às normas de convívio social.

Ressalto que neste mesmo estudo, Kehl (2003) também apresenta como característica da família contemporânea a sua capacidade de se reconstituir constantemente, segundo seu bem-estar, em busca de satisfação imediata. Com isso, possibilita novas formas de reconhecimento e representação, considerando, contudo, a manutenção das funções paterna e materna que devem ser exercidas por pessoas que se responsabilizem por esses cuidados.

A patologia, no entanto, incide à medida que os integrantes investem alto na continuidade familiar, de uma maneira demasiadamente individualista e narcísica, mesmo que a relação esteja marcada por comportamentos danosos, sentimentos confusos e com funcionalidade prejudicada, a exemplo do que ocorre nas relações incestuosas.

\section{Incesto}

Pensar nas diferentes dinâmicas familiares é considerar a existência de aspectos positivos ao sucesso e à saúde dos seus membros, assim como, quando irregulares, a revelação de formas disfuncionais e abusivas de relação.

Falar sobre violência sexual intrafamiliar é abrir a oportunidade para descobrir as particularidades das relações incestuosas, de vínculos conturbados, escondidos, obscuros para algumas famílias, que refletem a invasão não só do corpo, mas do psiquismo, da intimidade e das relações sociais das vítimas.

Um primeiro desafio na discussão da temática é conceituar incesto e refletir sobre quais características devem ser consideradas para tal. Esta dificuldade deve-se ao fato de que, encontrar características e definições exatas, é quase impossível ante a diversidade social, de culturas, com costumes próprios, que estruturam uma ordem social e que influenciam relações, principalmente a familiar. Apesar destas diferenças, Lévi-Strauss (1975) e Besson (1931) concordam que existe uma ordem maior, uma lei em todas as culturas que inviabiliza as relações incestuosas, o totem e o tabu.

Para Besson (1931), o totem constitui-se em um conjunto de regras que organiza as relações dos grupos. Determinadas leis advêm de um 
sistema, o qual define como "Sistema mágico-religioso e social", que é constituído por leis que regulam as relações entre membros do mesmo grupo, unidos fraternalmente por um vínculo sanguíneo, com as mesmas crenças, de forma a levar os mesmos nomes. Desta maneira, o totem regulariza tanto os comportamentos e costumes, quanto as possibilidades de uniões afetivo-sexuais dos seus participantes.

As relações afetivo-sexuais são formadas considerando essas regulações. A sua transgressão é tida como falta social muito grave e que pode também ser refletida por meio de ação variada, que age desde uma simples advertência à prisão ou pena de morte em algumas sociedades:

Porque a proibição do incesto apresenta, sem menor equívoco e indissoluvelmente reunidos, os dois caracteres nos quais reconhecemos os atributos contraditórios de duas ordens exclusivas, isto é, constituem uma regra, mas uma regra que, única entre todas as regras sociais, possui ao mesmo tempo caráter de universalidade. Não há praticamente necessidade de demonstrar que a proibição do incesto constitui uma regra. Bastará lembrar que a proibição do casamento entre parentes próximos pode ter um campo de aplicação variável, de acordo com o modo que cada grupo define o que entende por parente próximo. (Lèvi-Strauss, 1975, p. 45)

Observa-se que a interpretação sobre totem a interdição do incesto está intimamente ligada com as funções que cabem àqueles que cumprem a função paterna e materna, proposto por Kehl (2003), pois é daí que se pode estabelecer ordem e organizar as relações sociais locais. As relações afetivo-sexuais são formadas, neste sentido, considerando essas regulações e a sua transgressão é tida como crime social.

Para Sanderson (2005), o abuso sexual está relacionado assujeitamento de crianças e adolescentes, que ainda cultivam dependência, a atividades sexuais com adulto(s) ou outros que impõem seus desejos e fantasias, utilizando algum tipo de poder na busca de gratificação sexual pessoal. Neste contexto, a vítima não se sentirá capaz de reagir contrariamente devido ao desequilíbrio de forças as quais parece estar refém. O agressor, com isso, utilizará de encontros sexuais ou comportamentos que abrangem desde 0 aliciamento sexual, linguagem ou gestos sugestivos até o ato sexual com a vítima.

Azevedo e Guerra (1989) complementam a descrição de Sanderson (2005) entendendo o abuso sexual como todo ato ou jogo sexual, hetero ou homossexual, entre um ou mais adultos e uma criança/adolescente de até 18 anos, com finalidade de estimulação 
sexual sobre sua pessoa e/ou de outra pessoa. Os autores compreendem a violência sexual como de natureza erótica e pode apresentar-se de várias formas, veladas ou não, contemplando atividades com ou sem contato físico, como voyeurismo e cantadas obscenas, e com contato físico, a exemplo de beijos, carícias nos órgãos sexuais, até cópulas (anal, genital), sem ou com o emprego de força física.

Apesar da definição clara na literatura, a compreensão de ocorrências como esta nem sempre são adequadamente interpretadas, pois são comumente entendidos como carinhos especiais e cometidos por pessoas próximas, consideradas de confiança, as quais não imaginam que ser capazes de realizar atos:

Nas famílias com transações incestuosas, no seio das quais os estatutos afetivos e sentimentais são mal definidos, os códigos comportamentais são frouxos, o limite entre a afetividade e a sexualidade não é claro, um beijo na face pode ser interpretado como um convite sexual. Aí as relações não desenham fronteiras gestuais claras e, portanto, reasseguradoras. (Cromberg, 2001, p. 29)

Deve-se atentar que há uma controversa dúvida em nossa sociedade: a relação sexual incestuosa é considerada como relações entre pais e filhas (os), mães e filhos(as), entre irmãos, entre pessoas com consanguinidade de primeiro grau e/ou entre pessoas de segundo grau de parentesco. Porém, autores como Renshaw (1984) e Kehl (2003) ampliam a visão para este tipo de relação para além da consanguinidade já que os vínculos afetivos e de confiança ampliouse com as reconstituições familiares e as novas participações.

Segundo Forward e Buck (1989) e Cromberg (2001), a família incestuosa é caracterizada por relações fechadas, confusas, com papéis misturados, em que os filhos assumem responsabilidades e funções de outros parentes, misturando representações, sentimentos, confundindo desejos, fantasias e expressando novos tipos de relações com cada personagem familiar. O incesto, assim, revela um frágil equilíbrio em uma família que tenta evitar a separação conjugal paterna e a sua desintegração total.

Vale ressaltar que a relação afetivo-sexual incestuosa não gera vínculos frágeis, mas revela relação familiar problemática, com vínculos distorcidos, frouxos, limites e valores que não estão claros. Ferenczi (2011) e Cromberg (2001) aprofundam seus estudos considerando que a violência sexual incestuosa ocorre devido à existência de relações disfuncionais, de poder entre duas ou mais pessoas que buscam realização pessoal, ganhos e satisfação sexual em detrimento do sofrimento e submissão do outro, uma relação de oposição. 
$\mathrm{Na}$ constituição desse problema observa-se uma estrutura familiar afetada, caracterizada, conscientemente ou não, por atitudes manipuladoras entre elas. Ou seja, são identificados padrões relacionais abusivos de pessoas mais velhas ou mais fortes maiores contra mais frágeis, seja relação entre pais/padrastos/mães/madrastas e filhos, entre irmãos, tios ou avós, numa clara acepção de poder com o outro.

Nas relações familiares em que ocorre abuso sexual, os prejuízos ultrapassam o aspecto social, atingindo a saúde física e psíquica da vítima, como também afetar, ainda mais, toda a dinâmica familiar, os papéis, as responsabilidades e as ações entre si. Segundo Azambuja (2004), a família na qual ocorre o abuso sexual é disfuncional e perturbada na sua constituição, pois existe uma estrutura de poder, de posicionamento social, papéis e ações individualistas que, de certa forma, dificultam o convívio, mas que principalmente afetam significativamente o desenvolvimento psicossocial dos filhos em condições de normalidade.

Aproximando as afirmações de Dobke, Santos e Dell'aglio (2010) e Roselli-Cruz (2005), pode-se considerar que a relação sexual incestuosa pode acarretar em traumas maiores para crianças e adolescentes vítimas devido a desordem que gera ao estarem cientes de participar de uma ação interdita, com pessoas de sua convivência e que estão intimamente ligados a outros parentes, deixando-a vulnerável a descoberta desse evento. Neste momento é que os abusadores utilizam de mecanismos controladores e persuasivos com objetivo de assegurar o segredo e afirmando a relação dominadora que existe entre eles.

Segundo Magalhães (2005) e Dobke, Santos e Dell'aglio (2010) também observam manipulações diversas que proporcionam um estado confusional complexo no relacionamento entre os envolvidos. Ou seja, o primeiro ambiente de contato socioafetivo, que deveria proporcionar segurança, afeto e educação à criança e ao adolescente, trazem experiências de violação, uso de poder, transmissão de valores sociais inadequados, opressão, sentimentos de submissão e culpa, que refletem negativamente na construção de aspectos subjetivos destes.

Uma das consequências observadas nas famílias incestuosas é o número significativo de crianças e adolescentes que são retiradas de seu convívio familiar a fim de que sejam afastadas do agressor. Dessa maneira, estas são encaminhadas a instituições de acolhimento, dificultando seu direito de convivência familiar e retorno às atividades cotidianas, sendo esta mais uma situação de vitimização: culpabilizada pelo abuso e retirada do seio familiar. Nesse sentido, alertamos ao modo de dar significação às relações de poder e de gênero no nosso convívio social, perpetuando formas desiguais de relação. E como podem repercutir no convívio familiar? 
Pensar nisso é necessário, visto que a resolução pode estar no fortalecimento dos vínculos na busca da não dissolução do grupo de convívio ou, mesmo que temporária, mas não menos danosa, está na dissolução da família com a retirada de um dos entes, sem apoio adequado para o seu retorno.

\section{Metodologia}

Durante a pesquisa para a nossa Dissertação de Mestrado sobre as relações afetivo-sexuais de adolescentes vítimas de incesto, foram entrevistadas quatro meninas entre 12 e 18 anos com histórico de vivência incestuosa, em busca de relatos de experiência e expectativas das adolescentes sobre relações amorosas. A dissertação foi defendida na Pontifícia Universidade Católica de Minas Gerais em 2011.

Com a autorização da Secretaria Municipal da Assistência Social de Aracaju e a indicação dos casos acompanhados pelo Centro de Referência Especializado de Assistência Social local, as adolescentes foram convidadas para participar de entrevista. Estas jovens foram acolhidas em instituição local por terem sido molestadas por pais ou padrastos.

Para a entrevista, foi utilizado questionário pré-elaborado, mas que permitiam a inclusão de novas perguntas no transcorrer do encontro. Foram consideradas perguntas que refletissem sobre as relações sociais atuais, relações amorosas, família, amizade, sentimentos e emoções e relacionados a estes temas.

Suas falas e silêncios, de certo, ajudou a dissertar sobre o tema, mas trouxeram outros aspectos os quais consideraram importantes: a saudade dos familiares, o tempo na instituição, as expectativas quanto ao retorno às suas casas, dinâmica e convivência na instituição, dentre outras questões.

Um dado comum foi encontrado entre elas é que todas estavam a mais de dois anos separadas do convívio familiar, esperando resolução judicial, além de que tinham mais de um ano que não recebiam visita de familiares.

Ressalta-se que, para o trabalho dissertativo, foram utilizados nomes fictícios a fim de preservar suas identidades, assim como foram observados os preceitos éticos. A pesquisa foi submetida ao Conselho de Ética em Pesquisa da PUC Minas e aprovado sob o no 0306.0.213.000-09. 


\section{Os nós do acolhimento}

Parreira e Justo (2005) discutem os sentidos de filiação de crianças abrigadas. Em sua pesquisa, observam o desejo das crianças em recuperar a filiação familiar na busca de uma referência, de um lugar psicossocial. Para esses autores, a instituição coloca o sujeito em um lugar de passagem, em que os vínculos são temporários e as relações, muitas vezes, instáveis. Aos adolescentes reconhece-se 0 receio de ser visto diferente, como uma pessoa sem referência, sem família, lidando com as facetas do abandono, com a ausência de um lugar próprio, de uma história, em um tempo e espaço único, que não Ihes representam uma identidade definitiva.

[A situação de acolhimento] Significa deparar-se com a ausência da filiação primária constituída na vivência afetiva, que designe um lugar psicossocial sólido e seguro, um lugar que the assegure a possibilidade do desejo dentro dos parâmetros da lei, conectando-a assim a outros e com a cultura de maneira geral. (Parreira \& Justo, 2005, p. 176)

Pensemos, então, como esta instituição pode suprir as necessidades básicas do desenvolvimento biopsicossocial e sexual e servir como âncora para que as meninas de nossa pesquisa possam ter uma base, um lugar de referência para reconhecer a si, construir as próximas relações e localizarem-se socialmente se já se coloca como uma instituição de passagem?

Mesmo tendo que lidar com regras e normas da cultura institucional, Parreira e Justo (2005) apontam que a relação existente nestas instituições está baseada na caridade e piedade, um afeto transitório, dado por profissionais, voluntários e padrinhos que não possuem um lugar fixo na vida das crianças e adolescentes, e que tentam restituir algo que não está presente, está esvaziado, que é a própria filiação.

Esta característica pode ser observada quando as entrevistadas foram unânimes em comentar sobre a dificuldade em abordar questões pessoais com as funcionárias. Estas "não entendem" o que lhes é colocado e reagem sentindo-se obrigadas a seguirem as orientações institucionais e deixando de lado os questionamentos das adolescentes sobre relacionamentos sociais e afetivos. Sem respostas, as adolescentes são estimuladas e lembradas do relevo em priorizar os estudos.

Posicionando a respeito dos lares substitutos, Bowlby (2006) enfatiza a importância do cuidado no seio familiar diante da precariedade ou da insuficiência afetiva que uma instituição, ou mesmo uma mãe substituta, pode acarretar. Estudos descritos em sua obra atentam para a pouca efetividade de lares substitutos frente à necessidade afetiva e social da pessoa: 
Para a criança, a separação e a colocação num novo lar acabam sobrecarregadas por emoções como medo, apreensão, raiva, desespero e culpa, o que pode ser expresso sob tantas formas quantos forem seus mecanismos de defesa [...] a menos que a criança possa aceitar a necessidade da nova moradia, ela não poderá tirar proveito de sua experiência num lar substituto. Em seu esforço para negar a situação, suas energias são dirigidas, em fantasia ou na realidade, para o retorno à família. (Bowlby, 2006, p. 26)

Bowlby (2015) observa que, mesmo em lares com mães substitutas treinadas, a estrutura não oferece a segurança, a afetividade e a relação de união que um grupo familiar poderia oferecer. Neste sentido, mesmo com boa intenção profissional, é questionável sua capacidade colaborativa ao adolescente, diante de sua responsabilidade na formação subjetiva e parâmetros de relações afetivo-sexuais e sociais ante a experiências anteriormente observadas e a falta ou pouca referência nesses locais:

“Eu quero formar uma família, mas só que eu tenho medo, sabe tia. Porque homem fica com a gente, mas depois começa a traição, sabe. Aí deixa eu e meus filhos... [pensativa]. Por isso que eu tenho medo de casar, mas quero sim construir uma família, ter filhos." (Carmem)

"Olha, o casamento eu acho que é bom, é, porque constrói uma família, tem filhos, por um lado é bom, não sei" (Clarice)

Como a instituição poderá suprir as necessidades afetivas básicas no desenvolvimento psicossocial e sexual dessas jovens? Como esta mesma casa poderá reconstituir relações e auxiliá-las na elaboração de todas as ideias que trouxeram como bagagem da família a qual não mais convive?

É importante admitir que por melhor que seja o serviço oferecido, as elas têm suas limitações quanto ao atendimento de necessidades vitais dessas pessoas que precisam de uma relação íntima e contínua. Não se pode efetuar uma ruptura total entre a criança e adolescente e seu lar, nem proporcionar afeto as quais necessitam, trazendo em com isso, a sensação constante de insegurança e insatisfação entre essas adolescentes e a instituição (Bowlby, 2006).

Pode-se pensar que as dificuldades encontradas pelas entrevistadas em seus relacionamentos de amizade, assim como os afetivo-sexuais além de dificuldades de aproximação e de confiança com o outro, sensação e sentimentos vivenciados também na vivência familiar, podem ser reforçadas pelo distanciamento com os seus entes já que, não existem mais experiências afetivas complexas que possam reconhecer ou sanar as suas dúvidas. 
“Na escola eu não falo com quase maioria de ninguém. Agora aqui eu tenho mais [amigas da casa]. Na escola eu não acertava nada, tia, aí me chamavam de burra" (Gabriela)

Para Pereira e Justo (2005), os sentimentos de não pertença, as revivências edípicas, assim como as questões de cada fase são potencializadas ou vividas de uma maneira potencializada diante do desconhecimento ou a confirmação das reais intenções familiares quanto ao que viveu e ao que será, seu futuro. A herança psicológica de sua história não lhe é esclarecida e seu futuro está nas mãos de profissionais que decidirão seu destino, não a sua família.

"Só tenho duas amigas [referindo a duas internas. Confio nelas (...), só que eu tenho que passar muito tempo para confiar naquela pessoa e aí demoro a fazer amizades" (Carmen).

"Mais ou menos, acho que pouco, umas duas [quantidade de amigos]" (Carolina)

A insegurança que demonstram seja nos contatos sociais mais comuns como as amizades, as acompanham a todo momento da entrevista. Os cuidados profissionais, a convivência com outras garotas e colegas de escola parecem in suficientes para deixa-las a vontade. A dificuldade parece ainda mais acentuada quando falam de experiências amorosas quando lançam não acreditar na possibilidade de vivência amorosa satisfatória. As expectativas futuras são incertas e quanto a esta questão, demonstram ainda mais a fragilidade de falar em laços afetivos confiáveis e que não Ihes causem sofrimento.

“Minha preocupação mesmo é de me formar, ficar grandona, estudar, e quando for ver eu não sei de nada e minha mãe estar morta? Deus me livre e guarde." (Gabriela)

A expectativa de ser um profissional independente é outro ponto interessante durante as entrevistas. As adolescentes apresentam o discurso da instituição de que é muito importante ser independente financeiramente e autônoma. Esta ideia é reforçada pelos profissionais do local a fim de que elas se sintam estimuladas a empenhar-se a qual eles acreditam. Este discurso é apresentado como resposta rápida e automática, sem aparente afeto e logo justificada como uma orientação dos profissionais como algo que tende a não trazer problemas.

Durante as entrevistas, as adolescentes mostram-se desconfiadas, temerosas, algumas a ponto de mostrarem fisionomicamente desconforto ao tentar explicar seus sentimentos durante as entrevistas. Expressarem-se pode significar um risco de relembrar 
detalhadamente suas histórias ou de sentir-se ainda mais vulnerável por revelar medos, anseios e dificuldades.

$\mathrm{Na}$ instituição, estas jovens poderão encontrar a referência de como se portar, orientação pedagógica, desenvolvimento de algumas habilidades sociais, limites internos e externos, competência e perseverança. Porém, ela não consegue suprir a função materna sugerida por Kehl (2003), aos cuidados pessoais, individuais e de afeto necessários ao sentimento de pertença, sensação de segurança e de apoio emocional para as dificuldades presentes e futuras.

Pensemos que se a instituição assume a função de manter e orientar estas adolescentes vítimas de incesto e, ao mesmo tempo, encontra dificuldades em se aproximar delas para que possam auxiliá-las com questões específicas, elas também podem rememorar as dificuldades dos convívios anteriores com os seus parentes. Como foram separadas de sua família, sem seu consentimento, existe a possibilidade de reviverem uma relação distante, impositora e, simultaneamente, de submissão à figura que a instituição, o Estado e o judiciário assumem neste momento.

Bowlby (2015) aponta que os cuidados devem contemplar acompanhamento com profissionais qualificados, que considere a realidade de cada um, trabalhando aspectos de sua história, sua estadia na instituição, além de um trabalho com os pais, parentes e a supervisão dos profissionais que acompanham cada caso. Essa realidade não é a que observamos com frequência. Nesta pesquisa observou-se uma instituição que atende à necessidade de receber essas adolescentes, mas que não está qualificada às necessidades afetivas, sociais e psicossexuais pelo despreparo de seus profissionais e por sua restrita finalidade de acolhimento.

Diante de tantas considerações, o que esperar de efetivo desse lugar? As adolescentes expressam brevemente sobre visões de um ponto de vista pontual e do momento sobre suas vidas, mas nenhum deslumbre ou expectativa positiva de futuro. $O$ que estas adolescentes mudaram com esta vivência institucional? Quais as repercussões já que estão em um espaço as quais elas mesmas não conseguem definir, nem o que espera do seu futuro, das suas famílias e de suas vidas? Pelo o que foi observado a instituição não atende as demandas emocionais e afetivas de apoio que são importantes no desenvolvimento e aprendizagem importantes sobre relações sociais, amorosas, família, valores e tradições.

Nos quatros casos apresentados, a família se distanciou, pouco participando das atividades das adolescentes, bem como no acompanhamento das ações que o abrigo apresenta. Numa conversa informal com a coordenadora da instituição surgiu a mesma queixa da pouca participação dos familiares, que ficam por anos sem contato para receberem orientações e acompanharem suas filhas, demonstrando novamente um frágil vínculo que existe entre ambos. 
A instituição tenta suprir, mesmo sem condição e responsabilidades para tal, os papéis materno e paterno com estas adolescentes. Ao tentarem aproximação entre os reais responsáveis, aparecem dificuldades de contato, recusas, desinteresses que apontam para uma frouxidão e fragilidade e, de certa forma, um desamparo social e afetivo dessas famílias. As instituições também estão desamparadas por estas famílias, assim como as meninas também foram. Desse modo, as famílias também refletem para as instituições as suas próprias dificuldades, disfunções e experiências, reforçando com isso o ciclo de abandono e fragilidade.

Vemos, assim, que a negligência antes apresentada nos cuidados com os filhos, em suas relações, é transferida para quaisquer outros vínculos que se constroem com elas. Ressaltamos que, como apresenta em Azevedo e Guerra (1989), a negligência pode ser vista como uma falha ao cuidar das necessidades do filho, porém não deve ser considerada, necessariamente, uma intenção consciente ou proposital, mas é tida como uma inabilidade de comportamento dos pais. Ainda, para as autoras, a falta de atenção dos responsáveis pode levar a criança a experimentar sentimentos como insegurança, ansiedade e fobias em gradações variáveis, conforme o envolvimento ou o distanciamento dos adultos, em que o abandono está no último grau.

Mais uma vez, as vítimas de violência doméstica, no caso deste trabalho, mais especificamente a vítima de violência sexual incestuosa, continuam a viver o desamparo que antes presenciaram, mas agora em um outro ambiente, frio, distante, com afetos diferenciados e que neste momento, pouco representa quando comparado às lembranças, ou construções fantasiosas, de sua família.

Ressalta-se que, mesmo que esta relação reflita o desamparo, este o é para todas as partes. Não será, diante da ausência e compromisso dessas famílias, a instituição isenta de sua responsabilidade de intervir e fortalecer os laços entre a família e adolescentes acolhidas. É de tamanha importância que aquela esteja preparada para entender o tríplice desamparo, no qual estão envolvidas, com limitações e condições bem distintas, mas que precisam ser fortalecidos.

\section{Análise dos Resultados}

No desenvolvimento deste estudo, foi possível observar, através da literatura sobre o tema e pelo resultado das entrevistas realizadas, que a família é uma importante peça no processo de subjetivação, sendo mediadora entre o indivíduo e a sociedade, na qual se aprende a perceber o outro e o mundo. 
A contínua vivência familiar permite elaborar formas de relacionamentos possíveis, além de auxiliar os adolescentes a lidar com representações de afeto, convivência, valores e memórias importantes na constituição de conceitos e significados ao sujeito, até mesmo para as próximas relações construídas.

Para Pontes (2004), assim como para Bowlby (2006), Dobke, Santos e Dell'Aglio (2010), as crianças que são tiradas de seu grupo de convívio tendem a apresentar prejuízo decorrente da brutalidade da separação e do rompimento súbito da vivência familiar. Tal experiência desprovê a criança de modelo a observar, bem como tende a aumentar a fragilização dos vínculos, o aumento da desconfiança e da sensação de desamparo.

No caso das famílias com relações incestuosas, principalmente aquelas posteriormente desconstituídas após ordem judicial, podemos pensar sobre a repercussão de tais vivências na construção da identidade e subjetivação do sujeito. Como estas adolescentes estabelecerão relações afetivas equilibradas, com boas perspectivas e expectativas se desde cedo presenciaram vínculos confusos, ideias distorcidas e sentimentos dúbios a pessoas de convívio e que são responsáveis por seus cuidados? Não obstante, são separadas deste meio de formação para viver, por tempo incerto, em um ambiente o qual não havia vínculos ou referências anteriores. Como um serviço de acolhimento pode dar origem a novas percepções se aqueles que trouxeram algum sentido não as acompanharão?

Frente a esta realidade, a família, que é um dos pontos importantes da estruturação da vida psíquica, sai de cena para dar lugar a uma instituição de passagem, com vínculos e objetivos indefinidos para as adolescentes. É o modo característico familiar de organização da vida emocional de seus membros que faz transformar a ideologia dominante em uma visão de mundo, em um código de condutas e de valores, conforme visto na literatura. Mesmo aqueles que hoje não convivem no seio familiar, a inscrição dessa vivência está nos relacionamentos atuais: essas adolescentes continuam física e moralmente sem defesa, sentem-se fracas para protestas, mesmo em pensamento, contra a força e autoridade de um outro que pensa ser mais forte. Quando o medo atinge seu auge, assim como foi durante a experiência incestuosa, se submetem à vontade alheia esquecendo-se completamente de si (Ferenczi, 2011).

A dificuldade em expressar os sentimentos pode ser um aspecto característico da adolescência, mas nos casos de violência sexual, além das dificuldades de definir e compreendê-las, a introjeção ansiosa do agressor e das experiências sexuais incestuosas afetam o desenvolvimento psicossocial e sexual a ponto de despertar sentimentos ainda mais intensos e hipervalorizados, a exemplo da culpa e do medo, além de comportamentos de submissão e obediência como realidade intra-psíquica. Uma vez dentro, corre o 
curso do processo primário que age também na defesa patológica e no conteúdo. Neste sentido, as adolescentes seguem construindo ideias e alimentando sentidos em cima do trauma, em silêncio (Cromberg, 2001).

(...) crianças submetidas a qualquer tipo de abuso ou à negligência de necessidades básicas de dependência crescem apensas física e socialmente, enquanto emocionalmente continuam, de alguma forma, humilhadas, órfãs e prejudicialmente envergonhadas, reivindicando aquilo que não tiveram, tentando reparar, a qualquer preço, sua auto-estima, sua dignidade, narcisismo ferido. (Cukier, 1998, p. 32)

Decerto, a história com a família inscreveu um modo de estabelecer relações. No caso destas jovens, os estatutos afetivos e sentimentais são mal definidos e, como já apontou Cromberg (2001) e Ferenczi (2011), os vínculos continuam frouxos, sem demarcação entre afetividade e sexualidade, certo ou errado e sem que Ihes tragam a sensação de segurança. As instituições, por sua vez, pouco têm a oferecer na reelaboração subjetiva e afetiva, assim como a construção da identidade biopsicossocial.

Considerando a visão dos autores citados neste artigo, as adolescentes entrevistadas não encontraram e continuam sem encontrar um ambiente facilitador para que consigam ressignificar suas lembranças e interpretações. Somente alguém que realmente represente figuras paternas, maternas, fraternas e que estejam disponíveis a este tipo de vivência e responsabilidade, contribuirão significativamente.

Lembremos que estas são instituições com fim assistencial e sócio jurídico, por isso têm objetivos específicos em sua finalidade: acompanhar as adolescentes, provendo cuidados básicos até o fim do processo. Porém, elas precisam mais que isso para um bom desenvolvimento psíquico e social. Estes serviços de acolhimento têm limitações em suas estruturas e funções.

Podemos pensar em uma nova figura paterna que aparece e que regula, mantém, controla e exige limites. Podemos pensar em uma revivência edípica, neste caso, a revivência da dinâmica incestuosa com demarcações, segredos quanto a emoções e pensamentos, obediência.

Estas adolescentes, então, estão na condição de duplo desamparo. No primeiro momento, devido à desproteção familiar e à revivência incestuosa, ponto no qual toda esta história de sofrimento começou; e, em segundo, a condição de distanciamento e abandono familiar, com a maior importância para a ausência de suas mães nas atenções necessárias, além da incerteza sobre o seu futuro com o retorno aos cuidados familiares ou a continuidade na instituição. 


\section{Considerações finais}

Devemos considerar que o significado de vivências e relações interpessoais violentas com os familiares, seja física, psicológica e/ou sexual, reflete no desenvolvimento psicológico, social e sexual dos envolvidos.

Relacionamentos parentais com eventos de violência sexual mostram-se disfuncionais em sua dinâmica e não cumpridora dos deveres de proteger, educar e socializar, conforme expectativas sociais, revelando com isso outra possibilidade de construção cultural, escolhas e formas de relacionamentos sociais e afetivos das crianças e adolescentes. Desse modo, ao olhar a família, deve-se observá-la como ponto de referência na construção identitária de seus filhos. Por isso, em princípio, a família é o lugar mais apropriado para que crianças e adolescentes vivam.

No estudo, as adolescentes entrevistadas se mostram bastante vulneráveis e temerosas. Podemos creditar isto à experiência incestuosa e suas repercussões na formação das mesmas, porém, não se pode desconsiderar as que as sensações provocadas pelo afastamento do ambiente familiar podem reforçar o desequilíbrio psíquico, já antes constituído.

O distanciamento de relações afetivas benevolentes desencadeia sentimentos negativos quanto a pertença, aflição e angústia referentes às demandas de cada uma. Não surpreende que se observe distorções, sintomas e comportamentos, como quando da instalação desses, enquanto viviam a violência sexual, mesmo passados muitos anos. A introjeção dos sentimentos de medo, vergonha e culpa efetivados pelo agressor e a disfuncionalidade familiar desfez a confiança que tem de si e para com os outros. Poderá ser reconstituído longe da família, em uma organização?

São notórias as dificuldades socioafetivas das vítimas. A compreensão sobre as relações, valores, tradições e afetos, pouco serão adquiridas dentro de um espaço com condições restritas de ação.

Durante o acolhimento, ações de promoção a saúde estão disponíveis e de certo auxiliarão em algumas mudanças individuais, porém dentro das possibilidades de atuação dos serviços e dos profissionais. As questões relacionadas às vivências incestuosas e suas consequências, só poderão ser reelaboradas quando estes ocuparem o papel de coadjuvante na transformação da dinâmica familiar, caso contrário, a institucionalização só reforçará as ideias e sentimentos já atribuídos, além de intensificar à elas, vítimas, a responsabilização pela violência, o que é ainda mais traumático. 


\section{Referências}

Ariès, P. (1981). História Social da Criança e da Família. Rio de Janeiro: LTC.

Assis, S. G., \& Farias, L. O. P. (Orgs.). (2013). Levantamento Nacional das crianças e adolescentes em serviço de acolhimento. São Paulo: Hucitec.

Azevedo, M. A., \& Guerra, V. N. A. (Orgs.). (1989). Crianças vítimas da Síndrome do Pequeno Poder. São Paulo: Iglu.

Besson, M. (1931). Totemismo. Barcelona: Editorial Labor S. A.

Brasil. Estatuto da Criança e do Adolescente. Lei Federal $n^{\circ} 8069$ de $13 / 07 / 1990$.

Bowlby, J. (2015). Formação e Rompimento dos Laços afetivos (A. Cabral, Trad.). (5. ed.). São Paulo: Martins Fontes.

Bowlby, J. (2006) Cuidados Maternos e Saúde Mental (V. L. B. Souza \& I. Rizzini, Trad.). (2. ed.). São Paulo: Martins Fontes.

Cromberg, R. U. (2001). Cena incestuosa: abuso e violência sexual. São Paulo: Casa do Psicólogo.

Cukier, R. (1998). Sobrevivência emocional: as dores da infância revividas no drama adulto. São Paulo: Ágora.

Dobke, V. M., Santos, S. S., \& Dell'aglio, D. D. (2010). Abuso sexual intrafamiliar: da notificação ao depoimento no contexto processual-penal. Temas em Psicologia, 18(1), 167-176.

Ferenczi, S. (2011) Psicanálise IV (A. Cabral, Trad.). (2. ed.). São Paulo: WMF Martins Fontes.

Forward, S., \& Buck, C. (1989). A traição da inocência: o incesto e sua devastação (S. Flaksman, Trad.). Rio de Janeiro: Rocco.

Kehl, M. R. (2003). Em defesa da família tentacular. In G. C. Groeninga, \& R. C. Pereira (Coords.), Direito de Família e Psicanálise (pp. 163-176). Rio de Janeiro: I mago.

Lévi-Strauss, C. (1975). Totemismo Hoje (M. B. Corrie, Trad.). Petrópolis: Vozes.

Magalhães, A. P. (2005). Abuso Sexual Incestuoso: um tema centrado na criança e na família. Rio de Janeiro: Letra Capital.

Parreira, S. M. C. P, \& Justo, J. S. (2005). A criança abrigada: considerações acerca do sentido de filiação. Psicologia em Estudo, 10(2), 175-180.

Pontes, A. M. (2004). O Tabu do incesto e os olhares de Freud e LéviStrauss. Trilhas, 4(1), 7-14. Retirado de http://www.educadores.diaadia.pr.gov.br/arquivos/File/dezemb ro2013/sociologia_artigos/pontes_artigo.pdf

Porreca, W. (2011). Filhos no recasamento: estudo de caso em família em segunda união. (Tese de Doutorado), Universidade de São Paulo: São Paulo. Retirado de http://www.teses.usp.br/teses/disponiveis/59/59137/tde21102013-150422/pt-br.php 
Renshaw, D. C. (1984). Incesto (A. A. T. Serra, Trad.). São Paulo: ROCA.

Roselli-Cruz, A. (2005). Abuso sexual na infância: conceitos básicos e medidas de prevenção. In A. S. Silva, E. Senna, \& M. C. M. Kassar (Orgs.), Exploração sexual comercial de crianças e adolescentes e tráfico para os mesmos fins: contribuições para o enfrentamento a partir de experiências em Corumbá-MS. Brasília: OIT.

Sanderson, C. (2005). Abuso Sexual em Crianças: fortalecendo pais e professores para proteger crianças contra abusos sexuais e pedofilia. São Paulo: M. Books do Brasil Editora.

Stengel, M. (2003). Obsceno é Falar de amor? As relações afetivas dos adolescentes. Belo Horizonte: PUC Minas.

Singly, F. (2007). Sociologia da Família Contemporânea (C. E. Peixoto, Trad.). Rio de J aneiro: Editora FGV.

Zamberlan, C. O. (2006). Os novos paradigmas da família contemporânea: uma perspectiva interdisciplinar. Rio de Janeiro: Renovar.

\section{Endereço para correspondência \\ Aline Luiza de Carvalho}

Pontifícia Universidade Católica de Minas Gerais - PUC/MG

Avenida Prof. Alfredo Balena, 400, Centro, CEP 30130-100, Belo Horizonte - MG, Brasil

Endereço eletrônico: alineluizacarvalho@gmail.com

\section{Márcia Stengel}

Pontifícia Universidade Católica de Minas Gerais - PUC/MG

Avenida I taú, 525, Dom Cabral, CEP 30535-012, Belo Horizonte - MG, Brasil

Endereço eletrônico: marciastengel@gmail.com

Recebido em: 03/04/2016

Reformulado em: 15/09/2017

Aceito em: 15/09/2017

\section{Notas}

* Doutoranda de Psicologia.

** Profa. Dra. da Pontifícia Universidade Católica de Minas Gerais - PUC/MG e da Pós-graduação stricto sensu de Psicologia.

${ }^{1}$ CARVALHO, Aline L. Relacionamentos afetivo-sexuais de adolescentes vítimas de incesto. 2011. Dissertação (Mestrado em Psicologia) - Pontifícia Universidade Católica de Minas Gerais, Belo Horizonte.

Este artigo de revista Estudos e Pesquisas em Psicologia é licenciado sob uma Licença Creative Commons Atribuição-Não Comercial 3.0 Não Adaptada. 